\title{
MICROSTRIP PATCH ANTENNA FOR PCS AND WLAN
}

\author{
Ashwini Sawant ${ }^{1}$, M. M. Wankhade ${ }^{2}$, S. B. Takale ${ }^{3}$ \\ ${ }^{I}$ PG Student, Electronics Department, SCOE, Pune, Maharashtra, India. \\ ${ }^{2}$ Assistant Professor, E\&TC Department, SCOE, Pune, Maharashtra, India. \\ ${ }^{3}$ Assistant Professor, E\&TC Department, SCOE, Pune, Maharashtra, India.
}

\begin{abstract}
Due to development in wireless devices, it poses a new challenge for the design of an antenna in wireless communication. Patch antennas are well suited for various wireless application systems due to their low weight, low profile, versatility, conformability, low cost and low sensitivity to manufacturing tolerances. This paper present design, simulation of a rectangular micro strip antenna for WLAN and PCS. The aim of the work is to design reliable broadband, compact patch antenna for wireless devices. Antenna is proposed which is providing circular polarization, dual band, resonant frequencies at $1.9 \mathrm{GHz}, 2.4 \mathrm{GHz}$.
\end{abstract}

Key Words: Patch antenna, co-axial feeding, polarization, dual band, HFSS ...

\section{INTRODUCTION}

A wireless LAN is a flexible data communication network used as an alternative for a wired LAN. Primarily they are used in industrial sectors where employees are on the move, in temporary locations or where cabling may hinder the installation of wired LAN. Developments in LAN, Wireless LANs are being setup in home and offices it becomes more affordable. The increasing popularity of indoor wireless LAN capable of high-speed transfer rate is prompting the development of efficient broadband antenna. The broadband antennas are required to be compact, low-profile, directive with high transmission efficiency and designed to be discreet. Due to these requirements coupled with the ease of manufacture and repeatability makes the micro strip patch antennas very well suited for broadband wireless applications.

Rapid development in wireless communication system increases the demand of compact micro strip antenna with high gain and wide operating frequency. Micro strip antenna is more popular because it has advantages like low profile, conformal, light weight, low manufacturing cost and simple realization process, so it is also used in cellular phone, pagers, etc [1]. But it suffered from narrow bandwidth and polarization; therefore various techniques are used to improve the bandwidth of antenna [2] and to get circular polarization [9]. These includes decrease substrate permittivity, cutting slot on patch, increase patch height, use of various impedance matching techniques, feeding techniques and use of multiple resonators. In this paper we design a patch antenna for circular polarization and dual band [6] with compact size. It is having co-axial feeding, design on glass epoxy substrate to give wide bandwidth and maximum gain as well as radiating efficiency [3]. The proposed patch antenna is designed and simulated on ANSOFT HFSS software. These antennas are suitable for PCS (Personal Communication System) and WLAN (Wireless Local Area Network) system.

\section{BACKGROUND}

An antenna is a device used to transform a RF signal, travelling on a conductor, converts electrical signal into equivalent electromagnetic waves in free space. It is having property reciprocity i.e. reception and transmission of signal. Most of the antennas are resonant devices operate efficiently over narrow frequency band. Micro strip antenna have structure of three layers having ground plane, substrate and radiating patch as shown in fig.1. A rectangular patch used as a radiator having shape like circular, rectangular, pentagonal, hexagonal, etc. Patch made up of conducting material copper or gold. Substrate has material like FR-4, epoxy resin, synthetic, ceramic, etc [8]. For good performance of an antenna should have low dielectric substrate with thick dielectric substrate.

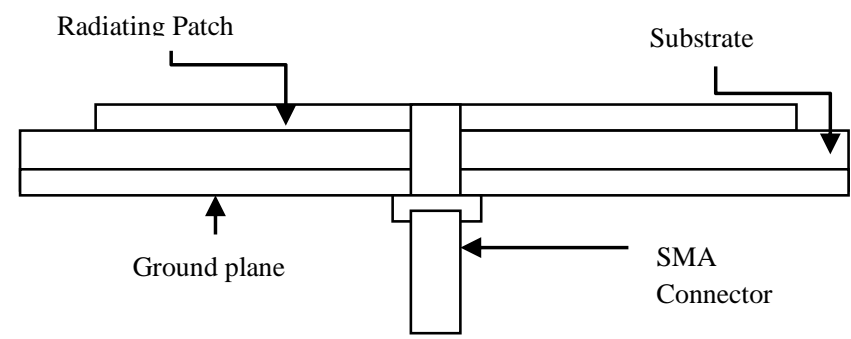

Fig.1 Structure of Micro strip Antenna

Various software packages like FEKO, HFSS, IE3D, CST Microwave Studio, ADS momentum, etc. are available for simulation of antennas. ANSOFT HFSS is used to simulate structure uses finite element method. It accurately characterizes the electrical performance of components and effectively evaluates signal quality like transmission path loss due to impedance match, reflection loss, parasitic coupling and radiation. 


\section{ANTENNA DESIGN}

Analysis of an antenna can be done by basically three type of model analysis [8].

1. Transmission-line model.

2. Cavity Model analysis.

3. Full wave analysis.

In transmission-line model rectangular microstrip antenna can be represented as an array of two radiating narrow apertures (slots), each of width $\mathrm{w}$ and height $\mathrm{h}$, separated by a distance $\mathrm{L}$, while in cavity model microstrip antenna by two slots, separated by a low-impedance Zc transmission line of length $\mathrm{L}$.

For proposed antenna analyzed by transmission-line model [8], $\mathrm{W}$ and $\mathrm{L}$ are width and length of patch respectively, $\mathrm{h}$ is height of substrate, $\varepsilon r$ is dielectric constant, $\mathrm{f}_{\mathrm{r}}$ is a resonant frequency, $\varepsilon_{\text {reff }}$ is effective dielectric constant. When $\mathrm{L} / \mathrm{h}>>$ 1 fringing is reduced. $\mathrm{W} / \mathrm{h} \gg>1$ and $\varepsilon_{\mathrm{r}} \gg>1$ the electric field lines concentrate mostly in the substrate.

$$
\begin{aligned}
& \frac{\mathrm{W}}{\mathrm{h}}>1 \\
& \text { creff }=\frac{\varepsilon r+1}{2}+\frac{\varepsilon r-1}{2}\left(1+12 * \frac{h}{W}\right)^{-0.5} \\
& \frac{\Delta \mathrm{L}}{\mathrm{h}}=0.412 * \frac{\left[(\operatorname{creff}+0.3) *\left(\frac{\mathrm{W}}{\mathrm{h}}+0.264\right)\right]}{\left[(\operatorname{\varepsilon reff}-0.258) *\left(\frac{\mathrm{W}}{\mathrm{h}}+0.8\right)\right]} \\
& \text { Leff }=\frac{1}{2 * \text { fr } * \sqrt{\varepsilon r e f f} * \sqrt{\mu 0 * \varepsilon 0}}-2 \Delta \mathrm{L} \\
& \mathrm{W}=\frac{1}{2 \mathrm{fr} * \sqrt{\mu \mathrm{o} \epsilon \mathrm{o}}} * \frac{1}{\sqrt{\left[\frac{2}{\varepsilon \mathrm{r}+1}\right]}} \\
& \mathrm{L}=\text { Leff }-2 \Delta \mathrm{L}
\end{aligned}
$$

Fig. 2 shows that geometry of proposed antenna, patch has length $\mathrm{L}=33.2 \mathrm{~mm}$ and width $\mathrm{W}=25.5 \mathrm{~mm}$, ground plane has length $\mathrm{L} 1=50 \mathrm{~mm}$ and width $\mathrm{W} 1=50 \mathrm{~mm}$, slot or perturbation area has length $\mathrm{L} 2=9 \mathrm{~mm}$ and width $\mathrm{W} 2=9 \mathrm{~mm}$. F is a feeding point on a patch.

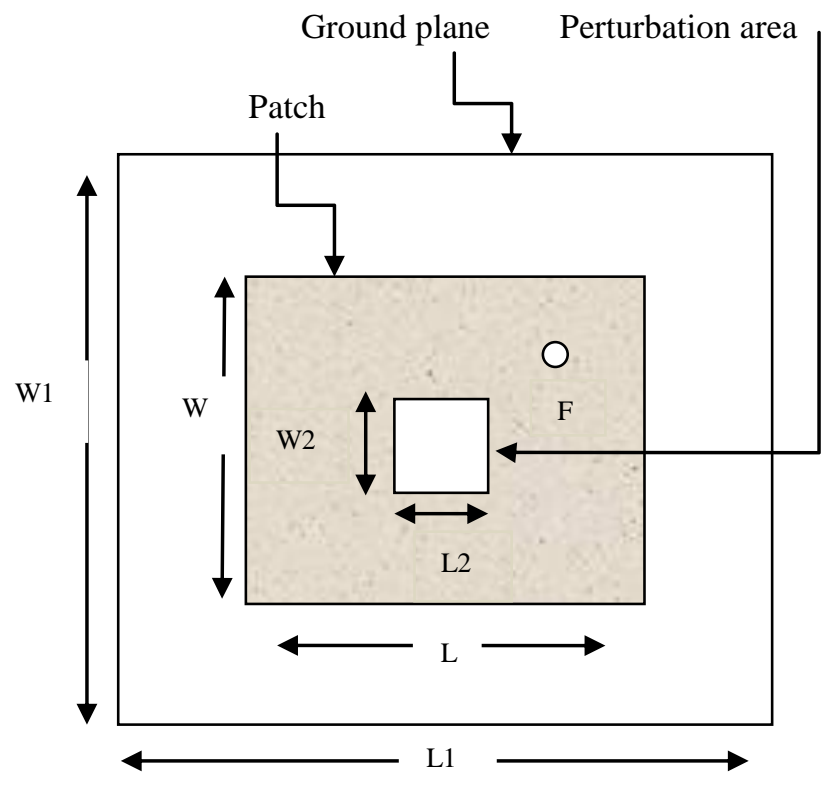

Fig. 2 Proposed Antenna
The software used to model and simulate microstrip patch antenna is HFSS. HFSS is a high performance full-wave electromagnetic field simulator for arbitrary 3D volumetric passive device modeling that takes advantages of the familiar Microsoft windows graphical interface [10]. It integrates simulation, visualizations, solid modeling and automation an easy to learn environment where solution of 3D problems are quickly and accurately obtained. Ansoft HFSS [11] employs the Finite element method, adaptive meshing and brilliant graphics for performance. Ansoft HFSS used to calculate parameters such as S-parameters, resonant frequency, fields, etc.

\section{RESULT AND DISCUSSION}

An antenna is simulated in a HFSS. Fig. 3 shows the structure of antenna in 3D model. It consists of patch having slot above to substrate and ground is below to substrate. It was assigned with air box boundary and virtual radiation to create far field radiation pattern and assigned with excitation.

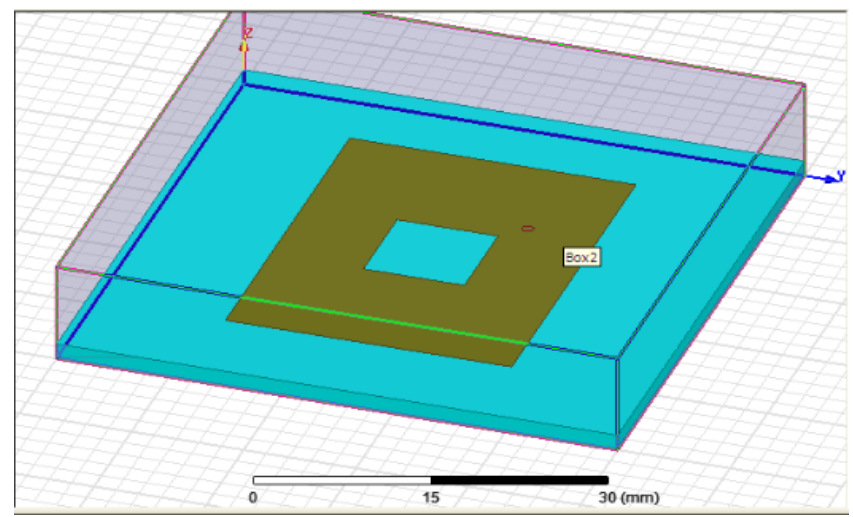

Fig. 3 Design of patch antenna in a HFSS

Antenna is simulated in an Ansoft HFSS. The parameters evaluated were return loss, impedance, bandwidth, polarization. Fig. 4 shows the return loss of proposed antenna having cutoff frequencies at $1.9 \mathrm{GHz}$ and $2.4 \mathrm{GHz}$.

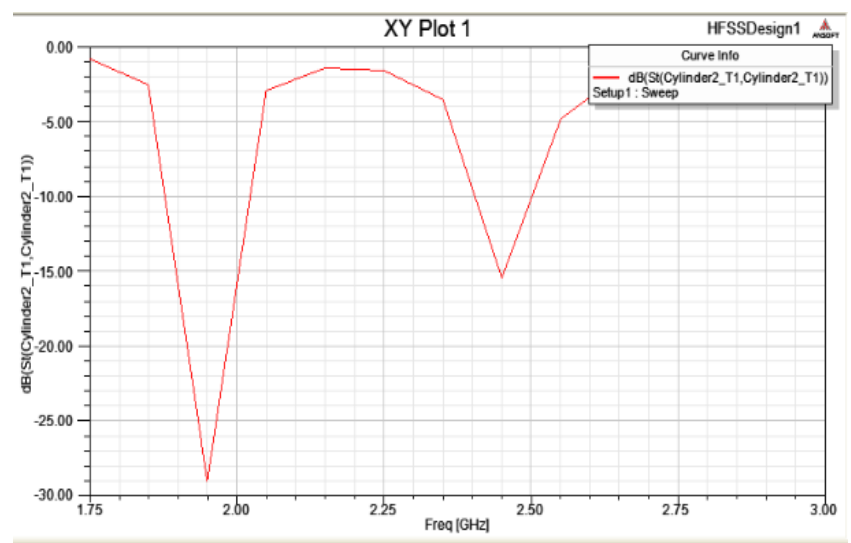

Fig. 4 Return loss of Antenna

Return loss specifies that input and output relationship between ports. If its value is $0 \mathrm{~dB}$ all power is reflected from antenna and it is $-10 \mathrm{~dB}$ then $3 \mathrm{~dB}$ power delivered to antenna and $7 \mathrm{~dB}$ is get reflected. From S-parameter 
bandwidth also calculated. It is nothing but the range of frequencies over which antenna radiate or receives energy. Here observed bandwidth is $180 \mathrm{MHz}$.

Fig. 5 shows that the variation of axial ratio with respect frequencies.

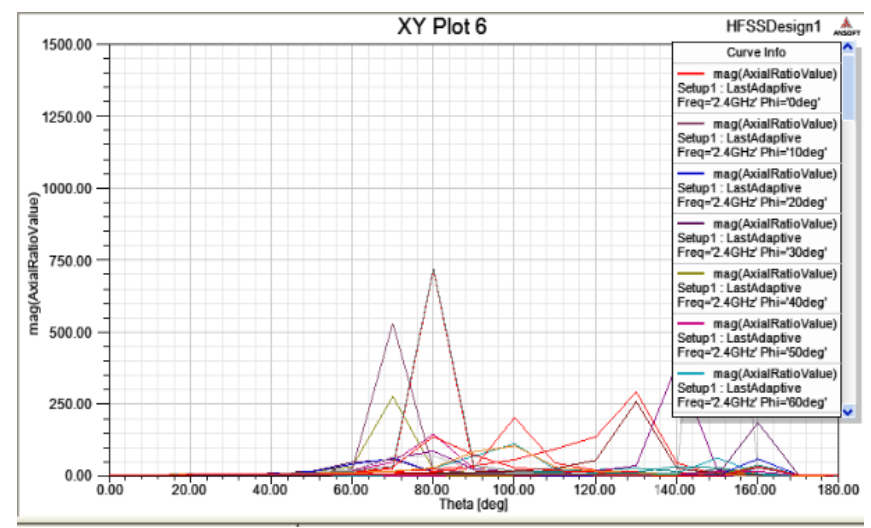

Fig. 5 Axial Ratio of an antenna

Axial Ratio is also measured in a result which is also various at different frequencies but at cut off frequencies it is near about less value near to $1 \mathrm{db}$. Here feed point adjusted until the axial ratio attains a minimum value. So the circular polarization is achieved.

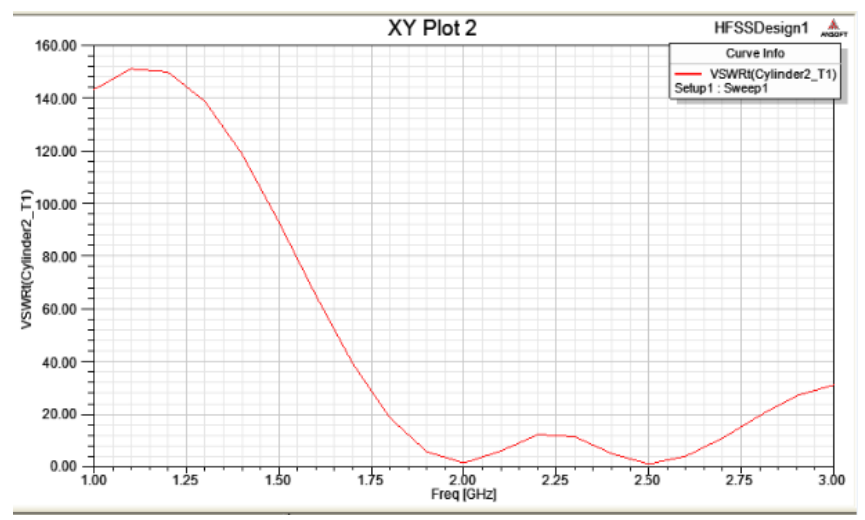

Fig. 6 VSWR of an antenna

Fig. 6 shows the graph of VSWR Vs. frequency. It is a function of reflection coefficient describes the power reflected from antenna. Ideally it should be low as it increases more power is reflect from an antenna.

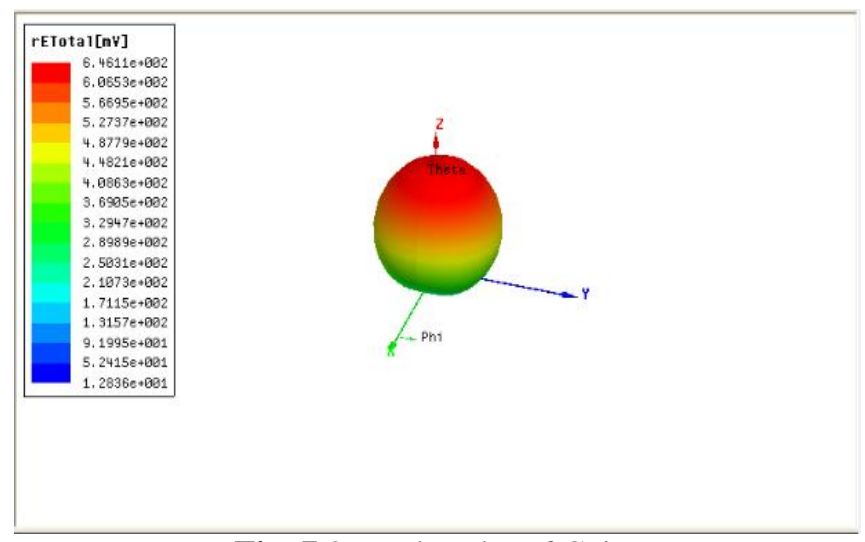

Fig. 7 3D Polar Plot of Gain
Polar plot shows the strength of radio waves from the antenna. Fig. 7 shows the gain of an antenna measured in dBi.

Smith chart is used to evaluate input impedance. It displays multiple parameters like impedance, admittance, reflection coefficients. For matching impedance value should be $50 \Omega$ which is observed from smith chart of an antenna.

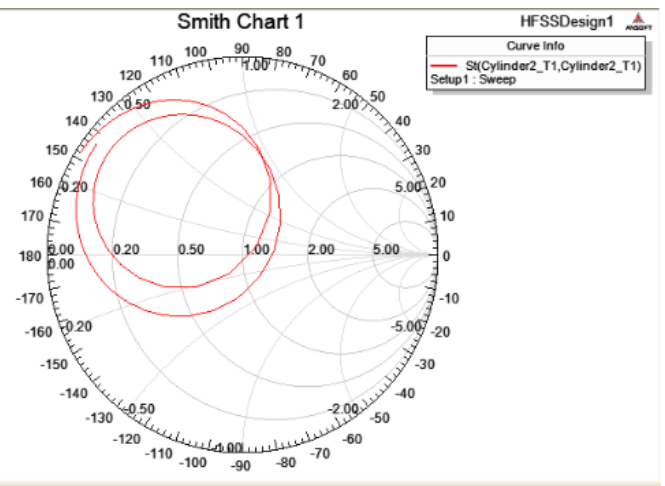

Fig. 8 Smith chart for proposed antenna

Here some observations are there which is shown in below table:

Table 1: I/P and O/P Parameters of an antenna

\begin{tabular}{|l|l|l|l|l|l|}
\hline $\begin{array}{l}\text { Feeding } \\
\text { Point(F) }\end{array}$ & $\begin{array}{l}\text { Length } \\
\text { of slot } \\
(\mathbf{m m})\end{array}$ & $\mathbf{F c}_{\mathbf{1}}(\mathbf{G H z})$ & $\mathbf{F c}_{\mathbf{2}}(\mathbf{G H z})$ & $\begin{array}{l}\mathbf{S 1 1}_{\mathbf{1}} \\
(\mathbf{d B})\end{array}$ & $\begin{array}{l}\mathbf{S 1 1}_{\mathbf{2}} \\
(\mathbf{d B})\end{array}$ \\
\hline 15,31 & 0 & 2.05 & 2.5 & -10 & -20 \\
\hline 15,31 & 9 & 1.9 & 2.42 & -14 & -20 \\
\hline $15.7,31.1$ & 9 & 2 & 2.5 & -6 & -11 \\
\hline $16.4,31.2$ & 9 & 2.1 & 2.5 & -6 & -12 \\
\hline $17.1,31.3$ & 9 & 2 & 2.5 & -11 & -11 \\
\hline $17.8,31.4$ & 9 & 1.8 & 2.5 & -6 & -9 \\
\hline $18.5,31.5$ & 9 & 1.9 & 2.45 & -20 & -16 \\
\hline
\end{tabular}

Table 2: I/P and O/P Parameters of an antenna

\begin{tabular}{|l|l|l|l|l|l|}
\hline $\begin{array}{l}\text { Feeding } \\
\text { Point(F) }\end{array}$ & $\begin{array}{l}\text { Length } \\
\text { of slot } \\
(\mathbf{m m})\end{array}$ & VSWR1 & VSWR2 & $\begin{array}{l}\mathbf{A R}_{\mathbf{1}} \\
(\mathbf{d B})\end{array}$ & $\begin{array}{l}\mathbf{A R}_{\mathbf{2}} \\
(\mathbf{d B})\end{array}$ \\
\hline 15,31 & 0 & 1 & 2 & 1.2 & 1 \\
\hline 15,31 & 9 & 2 & 2 & 1 & 1.1 \\
\hline $15.7,31.1$ & 9 & 3 & 1.5 & 1.3 & 1.1 \\
\hline $16.4,31.2$ & 9 & 3 & 2 & 1.2 & 1.2 \\
\hline $17.1,31.3$ & 9 & 2.6 & 2 & 1 & 1 \\
\hline $17.8,31.4$ & 9 & 1.3 & 1.6 & 1 & 1.1 \\
\hline $18.5,31.5$ & 9 & 1.2 & 1.3 & 1.2 & 1.1 \\
\hline
\end{tabular}

Different parameters are observed which is shown in Table 1 and 2. Here feeding points are according to dimensions is in 3D model of an antenna. Change in location of feeding point it changes the cut off frequencies and axial ratio of an antenna. From above work we have to achieve a dual frequency and circular polarization. For this achievement patch is having slot and it is feed diagonally. Feeding point is varying at different position to get best result. 


\section{CONCLUSIONS}

This paper presents the design and performance of Microstrip antenna having slot on a patch and substrate glass epoxy FR-4 using software tools HFSS. The designed antenna presents dual resonant frequencies having bandwidth $150 \mathrm{MHz}$ and Circular polarization. To achieve circular polarization axial ratio should be minimum i.e. near to $1 \mathrm{~dB}$ for that adjust a feeding point to a particular position to get minimum axial ratio. This improved parameter is achieved without increase in thickness of substrate. The characteristics of compact antenna are suitable for PCS (Personal Communication System) and WLAN (Wireless Local Area Network) so that it is used for mobile communication.

\section{REFERENCES}

[1]. Zakir Ali, Vinod Kumar Singh, Ashutosh Kumar Singh, "Wide Band Inset Feed Microstrip Patch Antenna for Mobile Communication", Proc. IEEE, pp. 978-0-7695-4958-3/13, 2013.

[2]. A. K. Singh, R.A. Kabeer, V. K. Singh, Z. Ali "Performance Analysis of First Iteration Koch Curve Fractal Log Periodic Antenna of Varying Angles" Central European Journal of Engineering (CEJE), Springer ISSN: 1896-1541Volume 3, Issue 1, pp51-57 March 2013.

[3]. Ali, Zakir; Singh, Vinod Kumar; Singh, Ashutosh Kumar; Ayub, Shahanaz "E shaped Microstrip Antenna on Rogers substrate for WLAN applications" Proc.IEEE,pp 342-345,Oct.2011

[4]. Mohammad Tariqul Islam, Mohammed Nazbus, Shakib, Norbahiah Misran, Baharudin Yatim, "Analysis of Broadband Microstrip Patch Antenna" Proc. IEEE,pp 758-761,Dec.2008.

[5]. Arvind Kumar Singh, Vinod Kumar Singh, Zakir Ali, Shahanaz Ayub, "Compact Wide Band Microstrip Line Feed Microstrip Patch Antenna for Wireless Application", International Journal of Computer Science \& Engineering Technology (IJCSET), Vol. 3 No.pp-100-105 4 April 2012.

[6]. S. H. S. Esfahlani, A. Tavakoli, and P.Dehkhoda, " $A$ Compact Single-Layer Dual-Band Microstrip Antenna for Satellite Applications", IEEE antennas and wireless propagation letters, Vol. 10, 2011.

[7]. Girish Kumar and K.P. Ray, "Broadband Microstrip antennas, Norwood" Artech House 2003.

[8]. C. A. Balanis, "Antenna Theory, Analysis and Design" John Wiley \& Sons, NewYork, 1997.

[9]. J. R. James and P. S. Hall, Eds., "Handbook of Microstrip Antenna". London: Peter Peregrinus, 1989.

[10]. www.AnosoftHFSS.com

[11]. ANSOFT High Frequency Structure Simulator v10 User's Guide.

\section{ACKNOWLEDGEMENT}

Author is thankful to Prof. S. B. Takale to his Guidance and Support and also thankful to Savitribai Phule University Pune for providing facility.

\section{BIOGRAPHIES}

Ashwini Sawant She completed B.E. from University of Pune. Presently she is Post Graduation student in Sinhgad College of Engineering, Pune and woking on a project "Microstrip antenna". She also presented a seminar on Image Compression Techniques.

Prof. M. M. Wankhade She is an Assistant Professor in Sinhgad College of Engineering, Pune. She persuaded her Master degree from SCOE, Pune. She guide different project to PG student. Her Area of Interest is Video Compression Techniques.

Prof. S. B. Takale He is an Assistant Professor in Sinhgad College of Engineering, Pune. He completed his Master degree from SCOE, Pune. He worked on Microstrip antenna Bandwidth enhancement during his PG Project. He has publication on Microstrip antenna design. He has very good practical knowledge of design an antenna. 